\title{
EL RECONOCIMIENTO DE LOS PUEBLOS INDÍGENAS EN LOS TEXTOS CONSTITUCIONALES. BREVE ANÁLISIS DEL DERECHO COMPARADO
}

\author{
Maximiliano Ravest Ibarra* \\ Pontificia Universidad Católica de Chile, Chile \\ maxravest@uc.cl
}

En el fondo de América sin nombre estaba Arauco entre las aguas vertiginosas, apartado por todo el frio del planeta. (...) Pero en las hojas mira el guerrero.

Entre los alerces un grito. (...). Cruza el cóndor su vuelo negro. (...) No hay nadie, sólo son los árboles.

Sólo son las piedras, Arauco.

(Pablo Neruda, "Canto General")

\begin{abstract}
RESUMEN: En nuestro país, el tema indígena ha adquirido cada vez mayor importancia; por ello este trabajo se propone analizar jurídicamente la problemática del reconocimiento constitucional de los pueblos indígenas, haciendo una breve mirada a la experiencia que han tenido otras países de América Latina y los datos particulares de los pueblos indígenas en Chile.
\end{abstract}

Palabras clave: reconocimiento, constitucional, pueblo, indigenas.

ABSTRACT: In Chile, the native issue, mainly related to our "mapuches", has reached a high degree of importance. So, this paper is intended to analize, from the law science point of view, the problems of the constitutional recognition of native peoples both in Chile and Latin America.

Keywords: recognition, constitutional, peoples, natives.

* Licenciado en Derecho de la Pontificia Universidad Católica de Chile. Ayudante de Cátedra de Derecho Constitucional de la misma casa de estudios y en la Academia de Ciencias Policiales. Ayudante de Investigación del Tratado de Derecho Constitucional de los profesores Alejandro Silva Bascunán y María Pía Silva (2008-2010). Minor en Ciencia Política del Instituto de Ciencia Política de la Pontificia Universidad Católica de Chile. 


\section{INTRODUCCIÓN}

Pablo Neruda en el Canto General hace una poesía descriptiva de América Latina y su historia, rescató los versos sobre el pueblo araucano, un pueblo valiente, que vive en hermosos parajes que se encuentran muy apartados del mundo.

Nos encontramos en un área con escasa investigación jurídica nacional, en donde nos vemos en la obligación de acudir a una mirada teórica y de cómo el derecho comparado ha enfrentado el reconocimiento constitucional de los pueblos indígenas, pero sin olvidar las particularidades de la realidad nacional. El tratamiento de los conceptos empleados es trascendental, ya que a parte de la regla general de las ciencias sociales que se ven afrontadas al problema terminológico, en esta materia en particular debemos ser sumamente cuidadosos con la terminología, porque tomar los conceptos en un sentido diverso trae aparejadas consecuencias jurídicas muy relevantes. El jurista debe estar atento a los actores políticos, en este caso los mapuches y los órganos del Estado, los cuales buscan imponer su visión y planteamientos. También hay que distinguir el sentir mayoritario de las etnias indígenas del de muchos líderes que son llevados a sus propias ideas y que lamentablemente emplean medios violentos.

El desafío de enfrentar la temática indígena es muy trascendental en un país como el nuestro donde su presencia es muy relevante, tanto desde un punto de vista cuantitativo como cualitativo.

\section{CONCEPTOS FUNDAMENTALES}

Antes de analizar la temática de este trabajo, considero pertinente hacernos cargo de conceptos fundamentales, algunos de los cuales están consagrados en las Bases de la Institucionalidad de nuestra Constitución (en adelante CPR), los cuales nos permiten tener un lenguaje común para abordar la temática del reconocimiento constitucional de los pueblos indígenas. Estos conceptos son los siguientes: Estado, Nación, Comunidad, Pueblo e Indígena.

El concepto de Estado es polisémico, es empleado en diversos sentidos por la ciencia jurídica, la ciencia política, por las ciencias sociales y en general por las personas. Nuestro constituyente a lo largo del texto constitucional lo emplea en diversos sentidos, por lo que es importante aclarar este concepto.

La definición más clásica del concepto de Estado es de Max Weber, quien lo define como "aquella comunidad humana que dentro de un determinado territorio (el territorio es el elemento distintivo), reclama (con éxito) para sí el monopolio de la violencia fisica legitima". Lo específico de nuestro tiempo es que a todas las demás asociaciones e individuos sólo se les concede el de- 
recho a la violencia física en la medida en que el Estado lo permite ${ }^{1}$. Por su parte, Carl Schmitt señala que "El Estado es el estatus político de un pueblo organizado en el interior de unas fronteras territoriales". 2

El profesor Silva Bascunán considera que con la mayor frecuencia, el vocablo "Estado" busca significar con él a la sociedad desde el punto de vista del derecho, de la organización que se da para conducirla al bien común, por ello se dice "que el Estado es unitario" (Art. 3 CPR), se le confía el cumplimiento de numerosos deberes (Art. 1 inc.5), se dice que está al servicio de la persona humana y que su finalidad es el bien común (Art. 1 inc.4). En un segundo sentido, el Estado es el conjunto de órganos e institucionales que lo representa, o sea, el aparato a través de cuyas decisiones y actuaciones se marcha hacia la realización del bien colectivo. Así se habla de los "órganos del Estado" (Art. 6 y 7 CPR). ${ }^{3}$

El profesor Vergara considera que término "Estado" se emplea en dos sentidos: i) el compositum sociológico estructural, el cuerpo político en su conjunto; y, ii) o cada uno de los "órganos del Estado" a los cuales el soberano delega su poder. ${ }^{4}$

Para efectos de este trabajo usaremos la palabra Estado en el primer sentido, o sea fundiendo las definiciones dadas anteriormente como "la sociedad o compositum sociológico, desde el punto de vista del derecho, de la organización que se da para conducirla al bien común en un territorio determinado, empleando las herramientas que le da el ordenamiento jurídico (entre ellas el uso lícito de la violencia), las que están limitadas por la dignidad humana y los derechos fundamentales", este concepto también tiene alcances relevantes para el derecho internacional, ya que sus normas no sólo obligan a las autoridades, sino a la sociedad entera que conforma el "Estado" de acuerdo a lo señalado en esta definición. Por otra parte, para referirnos al Estado en un segundo sentido emplearemos al vocablo "Órganos del Estado" cuando nos refiramos "al conjunto de órganos e institucionales que representan la "Estado" (como lo definimos), donde el soberano delega su poder".

Íntimamente ligado al concepto de Estado, se encuentra el concepto de nación, el que la RAE define, en la acepción que nos interesa, como "conjunto de personas de un mismo origen y que generalmente hablan un mismo idioma y tienen una tradición común".

1 Weber, Max. El Político y el Científico. Madrid: Alianza, 2003, pp. 83-84.

2 Uriarte, Edurne. Introducción a la Ciencia Política: la politica en las sociedades democráticas. Madrid: Tecnos, 2002, p. 76. Por su parte la politóloga Uriarte luego de analizar y criticar estas definiciones, señala que el Estado es la organización política de un pueblo en el interior de un territorio limitado por fronteras que se caracteriza frente a otras instituciones por posee el monopolio de la violencia fisica legitima, por dirigir y organizar el funcionamiento de la sociedad en todas sus esferas y por asumir el papel de regulador de las relaciones y encauzador de los conflictos de la sociedad'.

3 Silva Bascuñán, Alejandro. Tratado de Derecho Constitucional, Tomo IV -2da edición- Santiago, Chile: Editorial Jurídica de Chile, 1997, pp. 64-65.

4 Vergara Blanco, Alejandro. Apuntes de Clase, Derecho Administrativo I, Semestre I año 2009.

5 Diccionario de la Real Academia de la Lengua Española, <en línea>, [citado 25 de febrero de 2009]. Disponible en la World Wide Web: <http://www.rae.es>. 
Cuando hablamos de la nación, nos situamos en el plano de los ciudadanos, o del pueblo, "como conjunto de individuos unidos por unos rasgos y sentimientos comunes". Estados Unidos representa un caso interesante de democracia enormemente estable que integra a numerosas culturas en su seno, la idea de nación americana, que es una idea basada en un concepto político de nación. Existen, sin embargo, estados plurinacionales en los que la legitimación del Estado se ha mostrado más complicada por los nacionalismos étnicos, por ejemplo, en España. ${ }^{7}$

El filosofo Jacques Maritain sostiene que la nación es "es una comunidad de comunidades, un núcleo consciente de sentimientos comunes y de representaciones que la naturaleza y el instinto humano han hecho hormiguear en torno a un determinado número de cosas físicas, históricas y social”. Señala además que es acéfala, tiene sus élites y centros de influencia, más no jefe ni autoridad gobernante; estructuras, pero no formas racionales ni organizaciones jurídicas; pasiones y sueños, pero no un bien común; solidaridad entre sus miembros, fidelidad y honor, aunque no amistad cívica; maneras y costumbre, no orden y normas formales. ${ }^{8}$

El profesor Jaime Guzmán define nación como el "el sustrato espiritual que recorre el cuerpo social, que se orina en múltiples elementos de tipo geológico, étnico, ideológico, religioso, cultura, histórico, tradicionales, y que reconoce además un pasado común, una voluntad común en el presente y una unidad de destino en el futuro".

Considero que el concepto de nación adecuado para este trabajo es el que sintetizo como el "conjunto de personas de un mismo origen y que generalmente hablan un mismo idioma y tienen una tradición común, ligada a un territorio determinado". Toda nación, sea que lo tenga o no, reclama para sí un determinado territorio, el que muchas veces entra en pugna con los territorios que han determinados los Estados, por ejemplo: la nación vasca reivindica y se identifica con territorios presentes en España y Francia.

En el análisis de los distintos tipos de vínculos que forman los seres humanos, para este trabajo es pertinente hacerse cargo del concepto "comunidad" debido a que los indígenas agrupados comúnmente se los trata o se autodenominan como "comunidades indígenas". La RAE, en su acepción pertinente, define comunidad como un "conjunto de las personas de un pueblo, región o nación"10. En Sociología la comunidad se funda más que en el hecho, en la percepción que tienen varios de sentirse vinculados, mediante alguna forma de relación, con otras perso-

\footnotetext{
Uriarte, Edurne. op. cit. (n.2), p. 85.

Ibid., p. 87.

Silva Bascuñán, Alejandro. op. cit. (n.3), p. 173.

Rojas Sánchez, Gonzalo, et al. Derecho Político. Apuntes de las Clases del Profesor Jaime Guzmán Errázuriz. Santiago, Chile: Ediciones Universidad Católica de Chile, p. 96

10 Diccionario de la Real Academia de la Lengua Española, <en línea>, [citado 25 de febrero de 2009]. Disponible en la World Wide Web: <http://www.rae.es>
} 
nas ${ }^{11}$. Por lo tanto, la comunidad indígena la podemos definir como "un conjunto de indígenas del pueblo indigena, que se sienten vinculados por una relación étnica e historia común que data de tiempos precolombinos".

Nos falta responder una pregunta trascendental para este trabajo ¿Quién es indígena? La RAE lo define como "originario del pais de que se trata". ${ }^{12}$

Una primera definición legal la encontramos en la Ley 17.729 de 1972, sobre indígenas, y que crea el Instituto de Desarrollo Indígena, según la cual tienen la calidad de indígenas, independiente de si viven en comunidad o no, o del hecho de encontrarse ésta dividida, aquellas personas que habitando en cualquier lugar del territorio nacional, formen parte de un grupo que se exprese habitualmente en idioma aborigen y se distingan de la generalidad de los habitantes de la República por conservar sistemas de vida, normas de convivencia, costumbre, formas de trabajo o religión, provenientes de los grupos étnicos autóctonos del pais. ${ }^{13}$

La actual Ley Indígena, No 19.253, en su Artículo $1^{\circ}$ define y enumera algunas étnicas: "El Estado reconoce que los indigenas de Chile son los descendientes de las agrupaciones humanas que existen en el territorio nacional desde tiempos precolombinos, que conservan manifestaciones étnicas y culturales propias siendo para ellos la tierra el fundamento principal de su existencia y cultura.

El Estado reconoce como principales etnias indígenas de Chile a la: Mapuche, Aimara, Rapa Nui o Pascuenses, a las comunidades Atacameñas, Quechuas, Collas y Diaguita del norte del país, a las comunidades Kaweshkar o Alacalufe y Yámana o Yagán de los canales australes.

En el ámbito del derecho internacional encontramos definiciones como la Resolución 1.589 del Consejo Económico Social de las Naciones Unidad de 1971:

"las poblaciones indigenas están constituidas por los descendientes actuales de los pueblos que habitan el presente territorio de un pais total o parcialmente, en el momento que llegaron a él personas de otra cultura u origen étnico provenientes de otras partes del mundo, y que los dominaron y los redujeron, por medio de la conquista, asentamiento u otros medios, a condición no dominante o colonial; que viven hoy más en conformidad con sus particulares costumbres y tradiciones sociales, económicas y culturales, que con las instituciones del pais del cual forman parte ahora, bajo una estructura estatal en que se incorporan principalmente caracteristicas nacionales, sociales y culturales de otros segmentos predominantes de la población". ${ }^{14}$

11 Silva Bascuñán, Alejandro. op. cit. (n.3), p. 165.

12 Diccionario de la Real Academia de la Lengua Española <en línea>, [citado 25 de febrero de 2009]. Disponible en la World Wide Web: <http://www.rae.es>.

13 Silva Bascuñán, Alejandro. El Concepto de Pueblos Indígenas. Informe en Derecho, Santiago, 1992. Quisiera agradecer al autor de este Informe facilitarme este valioso material.

14 Ibid., p. 1. Don Alejandro Silva Bascuñán, en ese tiempo considera que esta definición es más perfecta que la que contempla la legislación vigente. 
Por su parte, el Convenio 169 de la OIT, sobre Pueblos Indígenas y Tribales en Países Independientes, señala, en su Artículo $1^{\circ}$, que sus normas se aplican a:

a) a los pueblos tribales en países independientes, cuyas condiciones sociales, culturales y económicas les distingan de otros sectores de la colectividad nacional, y que estén regidos total o parcialmente por sus propias costumbres o tradiciones o por una legislación especial;

b) a los pueblos en países independientes, considerados indígenas por el hecho de descender de poblaciones que habitaban en el país o en una región geográfica a la que pertenece el país en la época de la conquista o la colonización o del establecimiento de las actuales fronteras estatales y que, cualquiera que sea su situación jurídica, conservan todas sus propias instituciones sociales, económicas, culturales y políticas, o parte de ellas.

En síntesis son indígenas, para efectos de este trabajo, conforme al criterio del autor: "los descendientes de los grupos humanos precolombinos que fueron colonizados, conquistados y "pacificados" (dominados por el Estado de Chile), los que poseen una cultura y lengua propia, lo que los distingue del resto de la nación".

Finalmente nos hacemos cargo del conflictivo concepto de pueblo y pueblos. El conflicto se suscita porque son palabras polisémicas, y dependiendo de qué significado se les dé, podemos estar o no ante una inconstitucionalidad. Otra cuestión problemática es como se concilia el principio de igualdad con la existencia de un "pueblo" especial, ¿Por qué los indígenas deben tener un estatus jurídico distinto al resto de los chilenos? ¿Cómo ello es compatible con un Estado unitario o sociedad nacional?

La RAE define pueblo de diversas maneras: "Ciudad o villa", "Conjunto de personas de un lugar, región o pais", "Gente común y humilde de una población”, "País con gobierno independiente".

El profesor Silva Bascuñán define el pueblo, cuando se trata del elemento humano del Estado, como "un conjunto de personas humanas, racionales y trascendentes, que conviven en el grupo o sociedad mayor, formada por los individuos y sus familiar y, al mismo tiempo, por todos los grupos menores y sociedades, naturales y voluntarias, que desarrollan sus actividades en el seno de la colectividad"15. Estamos de acuerdo con este concepto, pero aún persiste la duda de si esta definición es compatible con la expresión "pueblos indígenas".

15 Silva Bascuñán, Alejandro. Tratado... (n.3), p. 183. Señala que en este caso pueblo es algo distinto de su población toda, o de la porción más necesitada de ella, o el electorado, o la categoría especulativa o todavía inorgánica de la nación, o de la raza, o de determinada clase social. 
En nuestro país del conflicto jurídico-constitucional, en relación al concepto de "pueblo" del Convenio 169 de la OIT ${ }^{16}$, fue zanjado por el Tribunal Constitucional en el ROL 309 ${ }^{17}$, haciéndose cargo del concepto de pueblo, considerando:

$38^{\circ}$ (...) debemos desestimar que el concepto "pueblo", tenga implicación alguna en lo que atañe a los derechos que pueda conferirse a dicho término en el derecho internacional, ya que lo establece en esas mismas palabras el artículo $1^{\circ}, \mathrm{N}^{\circ} 3$, del tratado en estudio. (...)

$44^{\circ}$ Que todo lo expuesto y, especialmente los propios términos de la Convención $\mathrm{N}^{\circ} 169$ cuestionada, es suficiente para que este Tribunal llegue a la íntima convicción que la expresión la expresión "pueblos indígenas", debe ser considerada en el ámbito de dicho tratado, como un conjunto de personas o grupos de personas de un país que poseen en común características culturales propias, que no se encuentran dotadas de potestades publicas y que tienen y tendrán derecho a participar y a ser consultadas, en materias que les conciernan, con estricta sujeción a la Ley Suprema del respectivo Estado de cuya población forman parte. Ellos no constituyen un ente colectivo autónomo entre los individuos y el Estado;

Frente a las dudas que implica la conciliación entre el concepto de pueblo, como elemento humano del Estado, y la expresión "pueblos indígenas", que la entendemos como "como un conjunto de personas o grupos de personas de un pais que poseen en común características culturales propias, que no se encuentran dotadas de potestades publicas y que tienen y tendrán derecho a participar y a ser consultadas, en materias que les conciernan, con estricta sujeción a la Ley Suprema”, el razonamiento del Tribunal Constitucional fue la aplicación de una interpretación armónica de la Constitución, línea jurisprudencial permanente desde ROL $33^{18}$, por lo tanto, se dio al concepto de "pueblos indígenas" el significado que le permite dar eficacia a todos los preceptos de

16 Artículo 1 No3. 'La utilización del término 'pueblos' en este Convenio no deberá interpretarse en el sentido de que tenga implicación alguna en lo que atańe a los derechos que pueda conferirse a dicho término en el derecho internacional'.

17 Requerimiento Formulado por Diversos Diputados Para Que El Tribunal Resuelva La Constitucionalidad Del Convenio No 169, Sobre Pueblos Indígenas y Tribales En Paises Independientes, Adoptado Por La Organización Internacional del Trabajo. Tribunal Constitucional de Chile, ROL 309, 4 de Agosto de 2000 <En línea> [citado 9 de Marzo de 2010] Disponible en la World Wide Web: <http://www.tribunalconstitucional.cl/index.php/sentencias/download/pdf/310>

A mayor abundamiento el TC en su considerando $43^{\circ}$ señala: El actual Presidente expresa: 'La palabra 'pueblos indígenas' está tomada, precisamente, en el sentido que se refiere al 'conjunto de personas de un lugar, región o país'. En tal sentido, dentro de un país existen distintos pueblos, distintos grupos de personas con identificaciones propias, pero no por ello cada uno conforma una 'nación'. Y más adelante expresa: 'Ninguna de las disposiciones del Convenio objetado implica o autoriza a los 'pueblos indígenas' a ejercer potestades públicas, elemento propio del ejercicio de la soberanía'. Y, finalmente, concluye: 'Es decir, el Convenio no innova en el ordenamiento jurídico, pues ejecuta una norma constitucional y se ajusta al sistema vigente. En tal sentido, de no existir, igual habría un mandato para ello que emana de la propia norma constitucional'.

18 Ibíd., Considerando 19 (...) 'La Constitución es un todo orgánico y el sentido de sus normas debe ser determinado de manera tal que exista entre ellas la debida correspondencia y armonía, excluyéndose cualquiera interpretación que conduzca a anular o a privar de eficacia algún precepto de ella'. 
la Constitución, entre ellos: los deberes del Estado, el principio de igualdad. Además consideramos que los pueblos indígenas reúnen las características propias de los grupos intermedios ${ }^{19}$. El Estado tiene el deber de contribuir a la mayor realización materia y espiritual posible de los pueblos indígenas, los que dada su condición merecen un especial respeto, promoción y fomento de sus actividades culturales y hacer constantes esfuerzos por valorar y promover su valiosa cultura, que hace más rica a la nación chilena, la que tiene su origen en la fusión poderosa de la culturas autóctonas y española. Hacer un trato especial para los indígenas no solo no vulnera el principio de igualdad, sino que lo hace verdaderamente efectivo, ya que al estar el "pueblo indígena” en una situación distinta del resto de sus compatriotas, deben tener un trato diferente, es ahí como se manifiesta la igualdad justa, lo que se condice con la jurisprudencia de nuestra Magistratura Constitucional. ${ }^{20}$

\section{MIRADA TEÓRICA AL RECONOCIMIENTO CONSTITUCIONAL DE LOS PUEBLOS INDÍGENAS. VENTAJAS Y DESVENTAJAS}

El tema del reconocimiento constitucional de los pueblos indígenas, es un tema reciente y que genera conflictos, en toda América Latina. La mayoría de las Constituciones de nuestro continente contienen reconocimiento constitucional de los pueblos indígenas, y además se les otorga expresamente ciertos derechos. En la medida que estos últimos sean mayores y comiencen a chocar con otros derechos fundamentales consagrados en las cartas fundamentales, la conflictividad es mayor.

Las dificultades que nos podemos encontrar en un reconocimiento constitucional de los indígenas, teniendo una mirada teórica son: la identificación del sujeto (los indígenas); la tensión entre individuo y comunidad en los derechos indígenas; la armonización entre el derecho nacional y el derecho indígena; y la tensión entre derechos de autonomía y derechos sociales. ${ }^{21}$

¿Por qué es importante identificar quien es el sujeto indígena? El tema del sujeto, que tiene evidentes connotaciones políticas y sociales, es relevante desde el punto de vista jurídico

19 Silva Bascuñán, Alejandro. Tratado de Derecho Constitucional, Tomo XII -2da edición actualizada- Santiago, Chile: Editorial Jurídica de Chile, 2008, p. 13.

20 Del Villar Mascardi, Waldo. Requerimiento de Inaplicabilidad por Inconstitucionalidad del artículo 61 de la Ley No 20.000 , sobre tráfico ilícito de estupefacientes y sustancias psicotrópicas. Tribunal Constitucional de Chile, ROL 1133, 18 de Noviembre de 2008, <En línea> [fecha de consulta: 9 de Marzo de 2010]. Disponible en la World Wide Web:<http://www.tribunalconstitucional.cl/index.php/sentencias/download/pdf/1045>.

Considerando 17: 'la igualdad ante la ley, puesto que ésta consiste en que 'las normas jurídicas deben ser iguales para todas las personas que se encuentren en las mismas circunstancias y, consecuencialmente, diversas para aquellas que se encuentren en situaciones diferentes' (sentencias roles $\mathrm{No}^{\mathrm{s}}$. 28, 53 y 219)'.

21 Carbonell, Miguel. La Constitucionalización de los Derecho Indígenas en América Latina: Una Aproximación Teórica, en: Boletín Mexicano de Derecho Comparado <En línea> nueva serie, año XXXVI, núm. 108, septiembre-diciembre de 2003, p. 839. [citado 6 de Marzo de 2010]. Disponible en la World Wide Web: <http://www.juridicas.unam.mx/publica/librev/rev/ boletin/cont/108/art/art2.pdf>. 
para determinar el ámbito personal de validez de las normas indígenas ${ }^{22}$. Respecto a la identificación del sujeto es importante definir a los indígenas, en este trabajo proponemos definirlos como: "los descendientes de los grupos humanos precolombinos que fueron colonizados, conquistados y "pacificados" (dominados por el Estado de Chile), los que posee una cultura e lengua propia, lo que los distingue del resto de la nación". Sin embargo, esta definición tiene problemas. El término "descendencia" genera múltiples posibilidad interpretativas, pues puede significar tanto la descendencia biológica o sanguínea como la mera descendencia digamos "cultural". Surgen preguntas como ¿La descendencia debe haberse mantenido pura? Ninguna etnia puede considerarse que ha mantenido históricamente su pureza. Tampoco la referencia a la colonización es muy afortunada, ya que no llegó a muchas regiones y en aquellas en que sí lo hizo fue en momentos históricos distintos. Otro elemento a considerar, que es recogido por nuestra legislación, es el que tiene que ver con la "conciencia de la pertenencia indígena", ya que al introducir elementos de carácter subjetivo, no se aporta demasiadas pautas sobre quien es o no indígena ${ }^{23}$. El intérprete tendrá que hacer un esfuerzo por entender estos conceptos en su sentido natural y obvio, mirando la finalidad de estas normas que es proteger y promover a estos grupos, y respetando la autoconciencia de las personas que se consideran indígenas, en base a antecedentes objetivos.

Otro problema a resolver es el de la titularidad de los derechos, hay ciertos elementos normativos que sugieren que el reconocimiento constitucional de los derechos indígenas está hecho en algunos casos para los indígenas considerados individualmente y en otros para los pueblos o comunidades indígenas ${ }^{24}$. Para solucionar este problema, el constituyente y legislador deben clarificar la cuestión, asignando expresamente los derechos de forma colectiva o de forma individual ${ }^{25}$.

Una de las principales reivindicaciones históricas de los pueblos indígenas ha sido la de contar con un "derecho al propio derecho". Esta aspiración ha sido satisfecha, como mayor o menor amplitud en América Latina, en nuestro país aún no hay consagración constitucional, pero la Ley Indígena estable un derecho propio de los indígenas. Las dificultades han surgido al momento de lograr una cierta armonía entre el sub-sistema jurídico indígena y el ordenamiento nacional ${ }^{26}$. Varias constitucionales en América Latina les han otorgado a los pueblos indígenas autonomía para aplicar su propio sistema jurídico, con el límite de los derechos fundamentales. Si el respecto debe ser amplio y total, la posibilidad de actuación de los usos y costumbres serían bastante limitadas; si ese respeto puede "ceder" o "matizarse" en algunos casos, el sub-sistema

22 Ibid., p. 843.

23 Ibid., pp. 845-846.

24 Ibid., p. 847.

25 Ibid., p. 849.

26 Ibid., p. 851. 
jurídico indígena tendría un mayor campo de actuación ${ }^{27}$. Hay casos que van más allá y reconocen la autonomía jurisdiccional para los pueblos indígenas la que está reconocida al menos en las Constituciones de Colombia, Ecuador y México ${ }^{28}$. En Chile, no hay tal consagración, incluso hubo un intento temerario de solicitar al Tribunal Constitucional la inaplicabilidad del " $\mathrm{C}$. Penal, de todos sus Códigos adjetivos, en especial el C. Procesal Penal y la Ley Orgánica sobre funcionamiento del Ministerio Público, 'en el territorio de los indígenas situados al sur del Bio Bio" por estar superpuestas sobre leyes y Tratados que en el derecho internacional se denominan Ius Cogens. La Magistratura Constitucional desestimo dicha acción constitucional por no cumplir los requisitos de admisibilidad, señalando en su considerando noveno: "no se da cumplimiento a la necesidad de la suficiente determinación del o de los preceptos legales que se consideren violatorios de la Carta Fundamental, a lo que debe agregarse que tampoco se explicita la supuesta contravención a la Constitución Política de la República". ${ }^{29}$

En el caso chileno, siempre el derecho indígena se sujeta a la Constitución y las leyes, y ha habido reticencia a reconocerles autonomía para aplicar su propio sistema jurídico. La reforma constitucional que aprobó la Comisión de Constitución, Legislación, Justicia y Reglamento del Senado, incorpora al Art. 4 el siguiente inciso final: "Los pueblos indígenas podrán organizar su vida de acuerdo a sus costumbres, siempre que ello no contravenga la Constitución y las leyes". Ello implica que la autonomía de los pueblos indígenas esta tan restringida como para el resto de los chilenos, todo cambia para nada cambiar.

Son varias las Constituciones de la región que reconocen, junto a la autonomía jurisdiccional, la autonomía política de los pueblos indígenas para elegir a sus gobernantes según sus usos y costumbres ${ }^{30}$. Considero que consagrar un derecho así es más complejo, ya que nuestra Constitución consagra que "Chile es un república democrática", es la norma que consagra el principio democrático, tan fundamental, que se podría considerar como una cláusula pétrea, el pueblo no puede dejar de ejercer la soberanía, este solo la delega en sus representantes democráticos. Lo que si consideraría razonable, es hacer ciertas modificaciones en los sistemas

Ibid., p. 852. El autor cita un caso real. En una comunidad indígena de Oaxaca, un hombre mató a su amigo en una reyerta, ambos en estado de embriaguez. El consejo de ancianos de la comunidad, como autoridad tradicional, decidió que el culpable, siendo soltero, debía casarse con la viuda de su víctima y sostener a los hijos de ésta. Enterada la autoridad judicial, quiso aprehender al asesino. La comunidad se negó a entregarlo. Luego se llamó al ejército, pero el gobernador para evitar un conflicto violento decidió respetar la decisión de la autoridad.

28 Ibid., p. 854.

29 Lincoqueo Huenumán, José. Requerimiento de Inaplicabilidad por Inconstitucionalidad respecto del Código Penal, de todos sus Códigos adjetivos, en especial del Código Procesal Penal y la Ley Orgánica sobre funcionamiento del Ministerio Público "en el territorio de los indígenas situados al sur del Bío- Bío". Tribunal Constitucional de Chile, ROL 1048, 13 de mayo de 2008, <En línea> [citado 7 de Marzo de 2010]. Disponible en la World Wide Web: <http://www.tribunalconstitucional.cl/index.php/sentencias/ download/pdf/854>.

30 Carbonell, Miguel. op. cit. (n. 21), p. 856. El autor cita el caso de México. Concretamente en el estado mexicano de Oaxaca, de sus 570 municipios, 412 eligen a sus autoridades por distintos sistemas consuetudinarios, y no a través del sufragio universal y secreto. Según informes de la OEA, dicha forma de elección es compatible con 'el pluralismo político, el derecho a la participación y la libertad de expresión’, aunque no sucede lo mismo en otros estados de la república mexicana, como es el caso de Chiapas. 
electorales, para permitir que resulten electos miembros que representen la diversidad del país, a través de primarias, un sistema electoral mixto, en definitiva más mecanismos de democracia semi-directa.

Por lo general, los grupos que, como los pueblos indígenas, reivindican cuestiones de reconocimiento, sufren también fuertes desigualdades por motivos económicos ${ }^{31}$. En el caso de Chile, los datos reflejan un mayor porcentaje de pobreza entre los indígenas en relación al resto de los chilenos. La encuesta CASEN $2006^{32}$ señala los siguientes datos: en la población no indígena hay un $3,1 \%$ de indigentes y un $10,2 \%$ de pobres no indigentes; en la población indígena hay un $4,7 \%$ de indigentes y un $14,3 \%$ de pobres no indigentes.

Finalmente, luego de ver todas estas dificultades ¿Hay alguna ventaja? La constitucionalización de los derechos indígenas, pesa a las tensiones que genera, arroja saldos que en un principio se pueden catalogar como positivos dentro del largo proceso de lucha para el reconocimiento de la dignidad de los pueblos indígenas. Su efecto más importante ha sido plasmar en textos jurídicos del máximo nivel la visibilidad que deben tener sus demandas, las que estaban rodeadas de silencio sin que se asumiera alguna responsabilidad por las condiciones miserables en que vivían y viven los indígenas. Es importante considerar sí, todas las dificultades que han enfrentado los demás países de América Latina, que revisaremos más latamente en este trabajo, por lo tanto me considero partidario de una reforma moderada, en que tal vez parezca que jurídicamente no cambien mucho las cosas, salvo reforzar la no discriminación a los indígenas y promover especialmente su cultura, pero que a la larga significan un reconocimiento, es decir, valorar el gran aporte al que han contribuido los indígenas a la conformación de la nación chilena.

\section{DERECHO COMPARADO}

\section{I. El Caso de Colombia}

En Colombia, la cuestión indígena desempeña un papel secundario en general. En buena medida ello guarda relación con el hecho de que la participación de los sectores indígenas en el total de la población no supera el $2 \% .{ }^{33}$

Con la puesta en vigencia de la nueva Constitución colombiana, el 7 de julio de 1991, comenzó una nueva era para los indígenas del país. Con la participación de tres representantes indígenas, la Asamblea Constituyente incorporó amplias disposiciones sobre el derecho indíge-

\footnotetext{
31 Ibid.

32 <En línea> [citado 7 de Marzo de 2010]. Disponible en la World Wide Web: <http://www.mideplan.cl/casen/publicaciones/2006/casen2006.pdf>.

33 Semper, Frank. Los derechos de los pueblos indígenas de Colombia en la jurisprudencia de la Corte Constitucional, en Anuario de Derecho Constitucional Latinoamericano, Fundación Konrad-Adenauer, Bonn, 2006, año 12, Tomo II, p. 762.
} 
na en el texto constitucional que en su conjunto conforman una constitución indígena. Según la jurisprudencia permanente de la Corte Constitucional, las disposiciones constitucionales y las regulaciones de la convención 169 de la OIT forman un bloque de constitucionalidad. ${ }^{34}$

La Corte Constitucional ubica el principio de la diversidad étnica y cultural, del Art. 735 de la Constitución, en una relación directa con los principios de democracia y pluralismo. ${ }^{36}$

Hay una particularidad en la Constitución colombiana: la consagración de la titularidad de los derechos fundamentales colectivos de las comunidades indígenas. Esto es un desvío de la concepción predominante de los derechos fundamentales individuales en el capítulo II de la Constitución. ${ }^{37}$

La Corte Constitucional enumera expresamente entre los derechos fundamentales de la comunidad indígena: ${ }^{38}$

- $\quad$ El derecho a la subsistencia a resultas del derecho a la vida (artículo 11 de la CP);

- El derecho a la integridad étnica, cultural, social y económica a resultas del derecho a la integridad física (artículo 12 de la CP), en particular como derecho a la defensa contra la desaparición forzada;

- El derecho a la propiedad de tierra comunitaria. Se consagra constitucionalmente la prohibición de vender o gravar las tierras comunitarias indígenas. El reconocimiento constitucional de la propiedad colectiva del resguardo sirve a la preservación de las culturas indígenas y de sus valores espirituales; 39

- El derecho a la participación en decisiones y medidas que pudiesen afectar a las comunidades indígenas, en particular relacionadas con la extracción de recursos naturales en sus territorios y artículo 330 de la CP (“Consulta previa”).

Mucho más difícil se plantea la inclusión y concreción del proclamado derecho indígena a la autodeterminación (autonomía) en la sistemática constitucional. En virtud de las consecuencias jurídico-internacionales que acarrea el derecho a la autodeterminación de los pueblos, los Estados son sumamente cautos en el reconocimiento de este derecho. Colombia no es la excepción. El concepto de autonomía es entendido como la capacidad de un grupo de darse for-

\footnotetext{
34 Ibid., pp. 762-763.

35 El Estado reconoce y protege la diversidad étnica y cultural de la nación colombiana. Art. 7 de la Constitución Política de la República de Colombia de 1991 (reformada en 1997).

36 SeMPer, Frank. op. cit. (n. 33), p. 764.

Ibid., p. 765.

Ibid., p. 766.

Ibid., p. 767.
} 
mas de organización social, económica y política propias. En la aplicación práctica del derecho, el trazado de límites de los territorios indígenas es una condición importante para una adecuada aplicación del derecho, la falta de la ley que lo hace ha creado permanentes problemas. ${ }^{40}$

La Corte Constitucional ha destacado reiteradas veces que sólo se habrá hecho justicia al artículo 7 de la CP una vez que se les conceda a las comunidades indígenas un máximo de autonomía. $^{41}$

Una manifestación especial de la idea de autonomía indígena es la constitución de una jurisdicción especial indígena con arreglo a lo estipulado en el artículo 246 de la CP ${ }^{42}$. La sistemática de la disposición sugiere que la jurisdicción especial indígena sería interpretada como otra forma más de jurisdicción especial, además de la jurisdicción militar. En ese sentido, forma parte de la justicia extraordinaria pero no extra estatal. ${ }^{43}$

En conclusión, Colombia tiene varias normas constitucionales en materia indígenas, las que consagran numerosos derechos colectivos e individuales, donde hay dificultades como: la productividad de las tierras; aplicación práctica de la consulta previa; y superar el antagonismo de entre unidad jurídica y pluralismos de derechos, en el ámbito de la jurisdicción especial indígena. ${ }^{44}$

\subsection{El Caso de MéXico}

La Constitución mexicana en su Artículo $2^{\circ}$, realiza un reconocimiento constitucional de los pueblos indígenas, establece una serie de derechos colectivos para los indígenas e impone una serie de deberes para los órganos del Estado.

La normativa constitucional en comento define al Estado mexicano como "único e indivisible" y que la nación tiene una "composición pluricultural sustentada originalmente en sus pueblos indigenas 45 ". Es una norma que busca armonizar la unidad y diversidad de un Estado. También se reconoce la "conciencia de su identidad" como criterio para identificar a los indígenas, los que se agrupan en comunidades. ${ }^{46}$

\footnotetext{
$40 \quad$ Ibid., pp. 770-771.

41 Ibid., p. 773.

42 'Las autoridades de los pueblos indígenas podrán ejercer funciones jurisdiccionales dentro de su ámbito territorial, de conformidad con sus propias normas y procedimientos, siempre que no sean contrarios a la Constitución y leyes de la República. La ley establecerá las formas de coordinación de esta jurisdicción especial con el sistema judicial nacional'. Art. 267 del Código Penal Federal.

43 Semper, Frank. op. cit. (n. 33), pp. 775-776.

44 Ibid., pp. 777-778.

45 La norma constitucional los define como 'aquellos que descienden de poblaciones que habitaban en el territorio actual del país al iniciarse la colonización y que conservan sus propias instituciones sociales, económicas, culturales y políticas, o parte de ellas'. Art. 2, inciso primero de la Constitución Política de los Estados Unidos Mexicanos.

46 'Son comunidades integrantes de un pueblo indígena, aquellas que formen una unidad, social, económica y cultural, asentadas en un territorio y que reconocen autoridades propias de acuerdo con sus usos y costumbres'. Art. 2 inciso tercero de la Constitución Política de los Estados Unidos Mexicanos.
} 
Luego el Artículo 2 letra A, le reconoce a los pueblos y las comunidades indígenas los siguientes derechos:

a) Decidir sus formas internas de convivencia y organización.

b) Aplicar sus propios sistemas normativos en la regulación y solución de sus conflictos internos, sujetándose a los principios generales de esta Constitución.

c) Elegir de acuerdo con sus normas, procedimientos y prácticas tradicionales, a las autoridades o representantes.

d) Preservar y enriquecer sus lenguas, conocimientos y todos los elementos que constituyan su cultura e identidad.

e) Conservar y mejorar el hábitat y preservar la integridad de sus tierras.

f) Acceder, con respeto a las formas y modalidades de propiedad y tenencia de la tierra establecidas en esta Constitución y a las leyes de la materia

g) Elegir, en los municipios con población indígena, representantes ante los ayuntamientos.

h) Acceder plenamente a la jurisdicción del Estado.

Finalmente el Artículo 2 letra B, impone a diversos órganos del Estado, para promover la igualdad de oportunidades, eliminar prácticas discriminatorias, garantizar el desarrollo y garantizar los derechos de los indígenas. Estos deberes se concretizan en los siguientes:

a) Impulsar el desarrollo regional de las zonas indígenas.

b) Garantizar e incrementar los niveles de escolaridad, favoreciendo la educación bilingüe e intercultural, la alfabetización, etc.

c) Asegurar el acceso efectivo a los servicios de salud.

d) Mejorar las condiciones de las comunidades indígenas y de sus espacios. Ampliar la cobertura de los servicios sociales básicos.

e) Propiciar la incorporación de las mujeres indígenas al desarrollo.

f) Extender la red de comunicaciones que permita la integración de las comunidades.

g) Apoyar las actividades productivas y el desarrollo sustentable de las comunidades indígenas.

h) Establecer políticas sociales para proteger a los migrantes de los pueblos indígenas.

i) Consultar a los pueblos indígenas en la elaboración del Plan Nacional de Desarrollo y de los estatales y municipales y, en su caso, incorporar las recomendaciones y propuestas que realicen. 
j) Para garantizar el cumplimiento de las obligaciones señaladas en este apartado, la Cámara de Diputados del Congreso de la Unión, las legislaturas de las entidades federativas y los ayuntamientos, en el ámbito de sus respectivas competencias, establecerán las partidas específicas destinadas al cumplimiento de estas obligaciones en los presupuestos.

Estamos ante una normativa extensa y rica en derechos, similar a la colombiana, con la diferencia que se concentra en un solo artículo. Lo que sí es diferente, es el importante porcentaje de población indígena en México, y el alto grado de conflictividad, como ocurre en el caso del Estado de Chiapas. Es importante rescatar de México los errores que se pudieren haber cometido al tratar este conflicto, para así buscar formas de solución de la violencia que se hace presente en la Región de la Araucanía.

\subsection{El Caso de Argentina}

El texto constitucional histórico de 1853-60, en su artículo 67 Inciso 15, aludía a la problemática indígena del siguiente modo: "Proveer a la seguridad de las fronteras; conservar el trato pacifico con los indios, y promover la conversión de ellos al catolicismo". El desfase provocado por el anacronismo de tal precepto era más que evidente. Con la modificación de la reforma de 1994, se introduce el numeral 17 en el artículo 75, una cláusula específica en materia de derechos de los pueblos indígenas argentinos, que textualmente expresa: ${ }^{47}$

"Articulo 75.- Corresponde al Congreso:

17. Reconocer la preexistencia étnica y cultural de los pueblos indigenas argentinos.

Garantizar el respeto a su identidad y el derecho a una educación bilingüe e intercultural; reconocer la personería jurídica de sus comunidades, y la posesión y propiedad comunitarias de las tierras que tradicionalmente ocupan; y regular la entrega de otras aptas y suficientes para el desarrollo humano; ninguna de ellas será enajenable, transmisible ni susceptible de gravámenes o embargos. Asegurar su participación en la gestión referida a sus recursos naturales y a los demás intereses que los afecten. Las provincias pueden ejercer concurrentemente estas atribuciones."

Se borra la antigua referencia a los "indios", ya que desde la perspectiva técnica es más exacta la palabra "indígenas", de raíz latina, que significa "originarios del país", que la voz "indios" que empleaba el tramo del precepto modificado, y que provenía de la convicción de los

47 BazÁn, Víctor. Los Derechos de los Pueblos Indígenas en Argentina: Diversos Aspectos de la Problemática. Sus Proyecciones en los ámbitos Interno e Internacional, en: Boletín Mexicano de Derecho Comparado <En línea> nueva serie, año XXXVI, $\mathrm{n}^{\circ}$. 108, septiembre-diciembre de 2003, p. 763 [citado 7 de marzo de 2010]. Disponible en la World Wide Web: <http://www. juridicas.unam.mx/publica/librev/rev/boletin/cont/108/art/art1.pdf>. 
descubridores de haber llegado a las Indias. Además se supera el anacronismo normativo de hablar de "conservar el trato pacífico con los indios" o de "promover la conversión de ellos al catolicismo". ${ }^{48}$

Llama la atención que el precepto en comento, se encuentra en la Segunda Parte sobre "Autoridades de la Nación”, Capítulo Cuarto sobre "Atribuciones del Congreso", por consiguiente sería un deber del Congreso Nacional hacerse cargo del derecho y política indígenas. Sin embargo, Víctor Bazán plantea que: "sin perjuicio de la localización geográfica de la aludida norma, ella entraña un mandato no sólo para los legisladores, sino también (y además de involucrar necesariamente al Poder Ejecutivo), para los jueces, quienes pueden y deben suplir la desidia o renuncia de los restantes poderes estatales". ${ }^{49}$

Además de la Constitución de la nación Argentina, el derecho público provincial comparado nos muestra que algunas Constitucional locales (además de cierta normativa infraconstitucional) han consagrado precepto que, con diferente tenor protector, plasman el reconocimiento de los derechos indígenas.

Del análisis de la doctrina judicial de la Corte Suprema de Justicia de la nación en la materia, no arroja un resultado demasiado fecundo, pues los fallos al respecto no son numerosos ni cualitativamente relevantes ${ }^{50}$. En este aspecto el caso de Argentina es similar al chileno, pero ello cambiara en la medida que se vaya aplicando el Convenio 169 de la OIT y se aprueba una reforma constitucional que reconozca a los pueblos indígenas.

\section{EL CASO CHILENO}

\section{I. Hecho JuRídico: los pueblos indígenas en Chile}

Chile tiene una población indígena relevante y en los últimos quince años el debate sobre las políticas públicas que deben aplicársele ha cobrado particular relieve. ${ }^{51}$

En el Censo de 1992 se consultó, a las personas de 14 años o más, sobre su eventual pertenencia a alguna de las siguientes culturas: mapuche, aymara, rapanui, o ninguna de las

\footnotetext{
Ibid., p. 764.

Ibid., p. 769.

Ibid., p. 772.

1 Donoso, Sebastián: Chile y el Convenio 169 de la OIT: reflexiones sobre un desencuentro. <en línea> Santiago, Chile: Vicerrectoría de Comunicaciones y Asuntos Públicos, Pontificia Universidad Católica de Chile. Temas de la Agenda Pública, Año 3 , No16, Abril 2008, p.1, [citado 8 de marzo de 2010]. Disponible en la World Wide Web: <http://vinculosconlasociedad.uc.cl/ documentos $/ 5 \cdot \mathrm{pdf}>$.
} 
anteriores. En el Censo de $2002^{52}$ se consideró a todas las personas y se aumentó el número de etnias. A la vez, se buscó centrar la pregunta en la pertenencia a un pueblo indígena, según las ocho etnias contempladas en la Ley ${ }^{53}$. Para ellos se utilizo el criterio de auto identificación de las personas consultadas. ${ }^{54}$

Los datos del Censo 2002, refleja que el total de la población nacional son: 15.116.435, de los cuales 692.192 pertenecen a un grupo étnico (hombres: 348.906; mujeres: 343.286) el que se desglosa de la siguiente manera: ${ }^{55}$

- $\quad$ Alacalufes: 2.622 (hombres: 1.423; mujeres: 1.199)

- Atacameños: 21.015 (hombres: 10.852; mujeres: 10.163)

- Región de Antofagasta: 13.855

- $\quad$ Aimara: 48.501 (hombres: 24.188; mujeres: 24.313)

- Región de Tarapacá (incluye las actuales regiones I y XV): 40.700

- Colla: 3.198 (hombres: 1.687; mujeres: 1.511)

- $\quad$ Mapuches: 604.349 (hombres: 304.580; mujeres: 299.769)

- Región de Valparaíso: 14.594

- Región del Biobío: 53.104

- Región de la Araucanía: 203.221 (23,4\% de la población de la región)

- Región de los Lagos (incluye las actuales regiones X y XIV): 100.327

- Región Metropolitana: 182.963

- Quechua: 6.175 (hombres: 3.037; mujeres: 3.138)

- $\quad$ Rapa Nui: 4.647 (hombres: 2.263; mujeres: 2.384)

- Región de Valparaíso: 2.671

- Región Metropolitana: 1.169

- Yámara: 1.685 (hombres: 876; mujeres: 809)

No deja de llamar la atención que hay más hombres indígenas que mujeres indígenas, cuando los datos de la población nacional indican un mayor número de mujeres, puede de-

52 El Artículo 6 de la Ley Indígena ( $n^{\circ}$ 19.253), señala: Los censos de población nacional deberán determinar la población indígena existente en el país.

53 El Artículo 1, inciso segundo de la Ley Indígena seńala: 'El Estado reconoce como principales etnias indígenas de Chile a: la Mapuche, Aimara, Rapa Nui o Pascuenses, la de las comunidades Atacameńas, Quechuas, Collas y Diaguita del norte del país1, las comunidades Kaweshkar o Alacalufe y Yámana o Yagán de los canales australes'.

54 CENSO 2002 Resultados. Volumen I. Población, País - Región, p. 192

55 CENSO 2002 Resultados. Volumen I. Población, País - Región, pp. 193-213. Se consideró el total de los indígenas a nivel nacional, desglosado en las respetivas etnias, y decidí colocar las regiones en que se concentra una mayor presencia de los indígenas. 
mostrar que los hombres se sienten más orgullosos de pertenecer a alguna etnia. El otro dato relevante, es que la región de la Araucanía tiene una cantidad de indígenas, concretamente de mapuches, muy relevante, que equivale al 23,4\% de la población regional. Además esta etnia, es la que tiene mayor presencia en el territorio nacional.

Aproximadamente un $65 \%$ de la población indígena vive en centros urbanos, dato relevante porque contraría un sesgo ideológico de la actual Ley Indígena en cuanto a que "lo indígena" esta íntima y necesariamente asociado a la ruralidad. ${ }^{56}$

Los indígenas viven un proceso de "pérdida cultural" que es particularmente acentuado en las generaciones más jóvenes, además tienen una tasa de pobreza significativamente más alta que el promedio nacional. La encuesta CASEN $2006^{57}$ señala los siguientes datos: en la población no indígena hay un 3,1\% de indigentes y un 10,2\% de pobres no indigentes; en la población indígena hay un $4,7 \%$ de indigentes y un $14,3 \%$ de pobres no indigentes. Otros indicadores socioeconómicos (ingreso, desempleo, educación, cobertura de salud, etc.) están en línea con lo anterior ${ }^{58}$. Por ello las demandas prioritarias siempre han sido requerimiento de tipo socioeconómicos y no demanda políticas (reconocimiento constitucional, esquemas de autonomía, representantes al Congreso, etc.) Los activistas y dirigentes indígenas más connotados, sin embargo, tienen un discurso principalmente centrado en cuestiones políticas, tales como el reconocimiento constitucional. 59

El proceso de colonización se caracterizó por un profundo mestizaje racial, intensos intercambios comerciales y, en general, una compleja red de relaciones inter-étnicas. Por lo que tenemos hoy, es una población indígena con altos niveles de integración -que algunos prefieren llamar asimilación- con el resto de la sociedad. ${ }^{60}$

Por lo tanto, ante esta realidad, hay que tener mucho cuidado con traer del derecho comparado normas en materia indígena que podríamos calificar de "avanzada", lo que no necesariamente se condice con las demandas mayoritarias de los pueblos indígenas. Sería poco razonable dar poder de autonomía a dirigentes indígenas que no han demostrado una actitud dialogante, sino todo lo contrario, muchas veces actuando con conductas terroristas, que en ningún sentido representan el sentir mayoritario de los mapuches, quienes aspiran a superar la pobreza, tener instancias de promoción de su cultura, terminar con las discriminaciones y en definitiva, que en la Constitución más que se plasmen tantos derechos, se consagre un reconocimiento y valoración de los indígenas a la nación chilena.

\footnotetext{
6 Donoso, Sebastián. op. cit. (n.50), p. 1.

57 <En línea>, [citado 7 de marzo de 2010]. Disponible en la World Wide Web: < http://www.mideplan.cl/casen/publicaciones/2006/casen2006.pdf>.

58 Donoso, Sebastián. op. cit. (n.50), p. 1.

59 Ibid., p. 2.

60 Ibid., p. 1.
} 


\subsection{Convenio i 69 de la OIT}

El Convenio se basa en la idea que los pueblos indígenas son sociedades permanentes llamadas a conservar su identidad, formas de vida y organización. Ello exige que los estados hagan un reconocimiento de la diversidad ética-cultural, afirmar y garantizar el respecto a una serie de derecho políticos sociales, económicos y culturales de los indígenas. ${ }^{61}$

Este convenio establece ciertos derechos de los pueblos indígenas: ${ }^{62}$

a) Derecho de decidir sus propias prioridades en los que atañe al proceso de desarrollo (artículo 7).

b) Derecho de conservar sus costumbres e instituciones propias, siempre que éstas no sean incompatibles con los derechos fundamentales (artículos 8 y 9).

c) Derecho a los recursos naturales existentes en sus tierras, los que comprenden su derecho a participar en la utilización, administración y conservación de dichos recursos (artículos 15).

d) Derecho de participación en la adopción de decisiones respecto a políticas y programas que les conciernan (artículo 6).

e) Derechos en materia de educación, cultura y lengua.

El Convenio correlativamente a los derechos, establece ciertos principios y obligaciones para los Estados parte: ${ }^{63}$

a) No discriminación (negativa).

b) Discriminación positiva.

c) Participación. Consultar a los pueblos indígenas.

d) Tierras o territorios.

i) Los gobiernos deberán respetar la relación de los pueblos indígenas con las tierras o territorios.

ii) Los pueblos indígenas pueden utilizar los recursos naturales de sus tierras, y a permanecer en ellas.

iii) Deberá reconocerse a los pueblos interesados el derecho de propiedad y de posesión sobre las tierras que tradicionalmente ocupan.

61 Ibid., p. 5. El Convenio 169 de la OIT en su preámbulo afirma que 'Reconociendo las aspiraciones de esos pueblos a asumir el control de sus propias instituciones y formas de vida y de su desarrollo económico y a mantener y fortalecer sus identidades, lenguas y religiones, dentro del marco de los Estados en que viven'.

62 Ibid., pp. 5-6.

63 Ibid., p. 6. 
e) Relocalización involuntaria. Como norma general los pueblos indígenas no deberán ser trasladados (artículos 16). Solo se los puede trasladar con consentimiento libre y de acuerdo a la legislación nacional.

Debemos recordar que estamos en presencia de un tratado internacional, o sea una norma jurídica de particularísimas características, que las analiza el Tribunal Constitucional en el Rol 309. Para el tribunal, las disposiciones programáticas o non self executing son aquéllas que requieren para su entrada en vigencia de la dictación de leyes, reglamentos o decretos. Estas disposiciones se reconocer por verbos rectores como: "los gobiernos deberán” o "deberán tomarse medidas". Según el tribunal, las normas programáticas no pueden ser inconstitucionales desde pronto, porque no son normas vigentes ni lo serán por obra del tratado y otras disposiciones, como algunas normas relativas a la solución de conflictos indígenas por órganos distintos de los tribunales (artículos 9) se salvan por estar inmersos en artículos condicionados a eventos de compatibilidad ${ }^{64}$.

Las implicancias jurídicas del Convenio dependen según el escenario:

- Si las normas se estiman como autoejecutables, una serie de derechos pueden ser exigidos por los indígenas, los Artículo 14 y 15, sería resistidos por la empresa privada.

- Si se adhiere a la doctrina del TC y se estima que todas o algunas normas no son autoejecutables, es posible que se reste dramatismo a su aprobación, pero aumentara la presión ara que se dicten nuevas normas.

- $\quad$ Es posible que los Tribunales de Justicia invoquen las normas del Convenio para dirimir contiendas.

Volviendo al eje central de este trabajo, que es analizar el reconocimiento constitucional de los pueblos indígenas, nos tenemos que hacer cargo de los planteamientos de un sector de la doctrina nacional, encabezada por Humberto Nogueira, que considera que los tratados de derechos humanos, como es el caso del Convenio 169 de la OIT, tienen rango constitucional, y que junto a los derechos fundamentales que consagra la Constitución, forma un bloque de constitucionalidad, en conformidad al Artículo 5 Inciso $2^{\circ}$ de la Constitución: "El ejercicio de la soberanía reconoce como limitación el respeto a los derechos esenciales que emanan de la naturaleza humana. Es deber de los órganos del Estado respetar y promover tales derechos, garantizados por esta Constitución, asi como por los tratados internacionales ratificados por Chile y que se encuentren vigentes". No comparto la opinión del connotado profesor, en base a los argumentos que ha dado la jurisprudencia del Tribunal Constitucional, particularmente en el Rol 346 ${ }^{65}$ :

64 Ibid., p. 7.

65 Requerimiento de inconstitucionalidad presentado por treinta y cinco señores Diputados respecto del Estatuto de Roma de la Corte Penal Internacional, adoptado en dicha ciudad el 17 de julio de 1998. Tribunal Constitucional de Chile, ROL 346, 8 de Abril de 2002 <En línea> [citado 9 de marzo de 2010]. Disponible en la World Wide Web: <http://www.tribunalconstitucional.cl/ index.php/sentencias/download/pdf/274>. 
$62^{\circ}(\ldots)$ la norma constitucional reformada no consagró que los tratados internacionales sobre derechos esenciales tuvieran una jerarquía igual o superior a la Ley Fundamental.

$63^{\circ}(\ldots)$ no estuvo en la mente del Constituyente que los tratados no quedaran sujetos a la supremacía de la Constitución.

$64^{\circ}$ (...) Rol No46 señalo expresamente que las normas constitucionales, en el orden interno, prevalecen sobre las disposiciones contenidas en tratados internacionales.

$65^{\circ}(\ldots)$ no procede enmendar la Constitución por la vía de un tratado internacional.

$67^{\circ}$ (...) Rol No 309, señalo que "si un tratado internacional contiene normas propias de ley orgánica constitucional, el acuerdo del Congreso para su aprobación o rechazo exige el quórum establecido por la Constitución para esa clase de leyes”

$68^{\circ}$ (...) Lautaro Ríos, señala: "Ninguna constitución contempla el logro automático de la jerarquía constitucional mediante un simple proceso semántico (...) Dicha pretensión también atenta contra el delicado mecanismo de reforma de la Carta Fundamental (...) que se caracteriza por su notable rigidez"

$69^{\circ}(. .$.$) que los tratados internacionales sobre derechos humanos puedan modificar la$ Constitución, conduce a que pierdan eficacia las disposiciones que permiten el control previo de constitucionalidad de los tratados (...) y el control a posteriori.

$70^{\circ}(\ldots)$ Llegaríamos al absurdo que mediante el quórum simple podría modificarse la Carta Política que exige el quórum de tres quintos o de dos tercios.

$72^{\circ}$ (...) el artículo $5^{\circ}$, inciso segundo, de la Ley Fundamental, no puede analizarse aisladamente y debe armonizarse con las siguientes disposiciones constitucionales (Art. 6, 82 No2 (93 No3), 80 (inaplicabilidad, 93 No6)).

75 (...) Alejandro Silva Bascuñán (...) expreso: "En la Comisión Ortúzar sostuvimos que dentro del ordenamiento jurídico chileno los tratados constituyen una jerarquía de normas que están por debajo de la Constitución, pero antes de la ley común y de todas las demás normas jurídicas que se dicten dentro del Estado"

Esta doctrina fue ratificada en el Rol $1288^{66}$, citando los argumentos señalados anteriormente, agrego:

66 Oficio de la Cámara de Diputados: Control de constitucionalidad del proyecto de ley, aprobado por el Congreso Nacional, que modifica la Ley No 17.997, Orgánica Constitucional del Tribunal Constitucional. Tribunal Constitucional de Chile, ROL 1288, 25 de agosto de 2009, <En línea> [citado 9 de marzo de 2010]. Disponible en la World Wide Web: <http://www.tribunalconstitucional.cl/index.php/sentencias/download/pdf/1214>. 
Cuadragésimo séptimo (...) tanto esta Magistratura como la Corte Suprema, antes de 2005, cuando era competente para conocer del recurso de inaplicabilidad, han considerado que la expresión "precepto legal" debe ser entendida en sentido amplio, incluyendo, por cierto, las disposiciones de un tratado internacional (sentencia de 24 de octubre de 1997, Rol No 33.097). El reconocer que un tratado internacional no es lo mismo que una ley no impide que éstos puedan asimilarse y que ambos queden comprendidos en la categoría de "precepto legal";

En base a los argumentos anteriormente señalados, nos atrevemos a afirmar que nuestro país no contiene un reconocimiento constitucional de los pueblos indígenas, de una manera que podríamos calificar como indirecta, ya que si acogiéramos la teoría del profesor Nogueira, el reconocimiento seguiría formalmente en la norma jurídica llamada "Convenio 169 de la OIT" y no en el texto de la Constitución.

Pero, ¿Cuál es la importancia del Convenio 169 de la OIT? La nueva ordenación se explica por haberse consolidado la convicción de que los indígenas debe convivir y progresar en una situación de igualdad con el resto de los chilenos y en un ambiente que no sólo rechace toda discriminación arbitraria, sino que favorezca el progreso y desarrollo de esa porción de nuestro conciudadadanos, dentro de una convivencia libre de acuerdo con su hábitos, lengua, creencias y cultura ${ }^{67}$.

\subsection{Proyecto de reforma constitucional, Boletines 5.324-07 y 5.522-07.}

Excede el ámbito de este trabajo hacernos cargo de los anteriores intentos de reforma constitucional que buscaban reconocer a los pueblos indígenas. Sin embargo, consideramos pertinente analizar el Informe de la Comisión de Constitución, Legislación, Justicia y Reglamento del Senado, recaído en dos proyectos de reforma constitucional, en primer trámite constitucional, sobre reconocimiento de los pueblos indígenas, Boletines 5.324-07 y 5.522-07.

El objetivo del proyecto es:

"otorgar reconocimiento constitucional a la existencia de pueblos indigenas en Chile, como demostración de respeto e interés de la nación chilena por sus tradiciones y su cultura, manteniendo la unidad de la nación; eliminar como factor de discriminación las consideraciones raciales o étnicas, y encomendar a la ley el desarrollo de lo que concierne a la protección de sus tierras y derechos de agua". ${ }^{68}$

67 Silva Bascuñan, Alejandro. Tratado de Derecho... (n. 3), t. XII, pp. 132-133.

Informe de la Comisión de Constitución, Legislación, Justicia y Reglamento del Senado, recaído en dos proyectos de reforma constitucional, en primer trámite constitucional, sobre reconocimiento de los pueblos indígenas, Boletines 5.324-07 y 5.52207 refundidos, p. 4, <En línea> [citado 27 de noviembre de 2010]. Disponible en la World Wide Web: <http://sil.senado.cl/ cgi-bin/index_eleg.pl?5324-07\%20y\%205522-07\%20\%28refundidos\%29,1,,S> 
Los aspectos que presentaron mayor dificultad en la construcción del acuerdo fueron el contenido de la expresión "pueblos indígenas", las modalidades del ejercicio de los derechos y el alcance de la protección de las tierras y las aguas. ${ }^{69}$

En la discusión sobre la expresión "pueblos indígenas" destaco: ${ }^{70}$

Senador señor Larraín (...) Lo que le parece peligroso, en cambio, es que se pueda dar a la expresión "pueblos indígenas" un significado que erosione el esfuerzo de construir una identidad nacional que abarque a todos sus componentes.

El Ministro señor Viera-Gallo aclaró: "la expresión "pueblos indígenas”, en el sentido de explicitar que tal concepto no confiere a sus integrantes el derecho a la autodeterminación política”.

La Ministra de Planificación, señora Paula Quintana: "Coincidió en que el reconocimiento es simbólico, pero subrayó que instalarlo en la Carta Fundamental viene a saldar una deuda de nuestro ordenamiento jurídico con los pueblos originarios y sus culturas, que integran nuestra identidad nacional.

Senador señor Ruiz-Esquide (...) muchos de ellos (los indígenas) no están imbuidos del sentimiento de ser chilenos o argentinos, sino que se consideran originarios, esto es, pobladores y dueños del territorio.

En la discusión sobre los derechos de los pueblos indígenas destaco: ${ }^{71}$

Senador señor Espina manifestó que la dificultad en esta materia está dada porque la definición de quien representa a los pueblos originarios.

Senador señor Chadwick aclaró que gran parte del texto que se discute es de carácter simbólico, porque ya está cubierto por la Constitución y la legislación.

En la discusión sobre Protección de las tierras y las aguas destaco:

Senador señor Larraín expresó que no hay duda en cuanto a la existencia de derechos ancestrales a la tierra (...) Pero cosa distinta es el agua, pues, con la sola excepción de las comunidades del norte, los derechos sobre ellas deben constituirse de acuerdo con las prescripciones del Código de Aguas, sin distinguir según quien los solicita.

\footnotetext{
69 Ibid., pp. 10-11.

70 Ibid., pp. 11-13.

71 Ibid., pp. 13-15.
} 
Senador señor Espina manifestó que el reconocimiento de las aguas ancestrales le parece razonable, porque las tierras sin agua son de escaso o nulo valor. Sin embargo, como los derechos de agua están prácticamente copados y no hay disponibles, cuando el propietario rehúse venderlos se habrá generado un conflicto de proporciones. Propuso acotar las cuestiones involucradas en el reconocimiento constitucional de los pueblos originarios a las más esenciales, dando así satisfacción a la gran mayoría, porque siempre habrá grupos más radicalizados que encontrarán todo insuficiente.

El Ministro señor Viera-Gallo explicó (...) la intención del Ejecutivo no es innovar en el estatuto juridico de las aguas en Chile, sino asegurar que el reconocimiento de los derechos de los pueblos e individuos a las aguas, conforme a la normativa actual.

El Fiscal de la Dirección Nacional de Aguas, señor Fernando Valdés, explicó (...) la constitución originaria del derecho de aprovechamiento de aguas se hace a través de un procedimiento administrativo público, que termina con una resolución del Director General de Aguas (...) no hay base legal especial que permita establecer un mecanismo de expropiación de derechos de agua para este fin (que los indígenas tengan agua) (...) los derechos ancestrales dan pie a constituir derechos de aprovechamiento de aguas, según el régimen general.

Senador señor Larraín (...) Las obras hidráulicas se iniciaron en el valle central en el siglo XIX, por tanto, no es posible afirmar que existen derechos indigenas de aprovechamiento de aguas de carácter ancestral, y establecer en la Constitución Política de la República un derecho indígena de aguas es crear un nuevo estatuto jurídico que entrará en conflicto, inevitablemente, con el actual régimen de derechos de aprovechamiento de aguas.

El señor Ministro Secretario General de la Presidencia expresó que no es la voluntad del Ejecutivo generar un problema constitucional

Senador señor Larraín observó que una inserción constitucional como ésa no tiene sentido porque la Constitución actual ya garantiza al titular su derecho de aprovechamiento de aguas constituido según las normas legales, sin distinguir si ese titular es o no indígena.

El señor Fiscal Nacional de Aguas puntualizó que la DGA interpreta que en nuestro ordenamiento jurídico no hay derechos de propiedad sobre las aguas, sean estos de indígenas o de no indígenas, solamente hay derechos de aprovechamiento de aguas (...) el inciso final del número $24^{\circ}$ del artículo 19 de la Constitución habla de derechos de aguas "reconocidos o constituidos en conformidad a la ley", y el Código de Aguas ha establecido dos procedimientos para desarrollar la norma constitucional 
Finalmente se decide refundir la moción de los Senadores de RN con el Mensaje del Ejecutivo, lo que fue aprobado por 4 votos a favor (Alvear, Gómez, Espina y Chadwick) contra 1 (Muñoz). La mayoría apoyo la propuesta porque consideran que la norma aprobada es un buen punto de partida para el debate. El senador Pedro Muńoz voto en contra porque para el partido socialista es fundamental que los pueblos indígenas sean sujetos de derechos.

El texto aprobado es el siguiente:

\section{PROYECTO DE REFORMA CONSTITUCIONAL:}

"Artículo único.- Introdúcense las siguientes enmiendas en la Constitución Política de la República:

1) Reemplázase el artículo $4^{\circ}$ por el siguiente:

"Artículo $4^{\circ}$.- La Nación chilena es una, indivisible y multicultural.

El Estado reconoce la existencia de los pueblos indígenas que habitan su territorio y el derecho de sus comunidades, organizaciones e integrantes a conservar, fortalecer y desarrollar su identidad, cultura, idiomas, instituciones y tradiciones y a participar en la vida económica, social, política y cultural del país en la forma que establece el orden jurídico nacional.

Los pueblos indígenas podrán organizar su vida de acuerdo a sus costumbres, siempre que ello no contravenga la Constitución y las leyes.”.

2) Intercálase en el artículo $5^{\circ}$ el siguiente inciso primero, nuevo: "Artículo $5^{\circ}$.- Chile es una república democrática.”.

3) Intercálase, en el párrafo primero del número $2^{\circ}$ del artículo 19 , entre las palabras "mujeres" y " son", la siguiente frase, entre comas: "cualquiera sea su origen étnico o racial".

4) Agrégase al número $24^{\circ}$ del artículo 19 el siguiente párrafo final, nuevo: "La ley protege la propiedad sobre las tierras de las personas y comunidades indígenas y sus derechos de aprovechamiento de aguas conforme lo establecido en la Constitución y las leyes.”

5.4. Consecuencias jurídicas del texto aprobado por la Comisión de ConstituCión, Legislación, Justicia y Reglamento del Senado

Considero que la reforma constitucional aprobada en la Comisión es moderada, no tiene grandes pretensiones, no se va a generar un gran cambio en la estructura jurídica de nuestra constitución, es clara la intensión del constituyente durante la discusión parlamentaria donde se planteó: 
La Ministra de Planificación, señora Paula Quintana: “Coincidió en que el reconocimiento es simbólico,

Senador señor Chadwick aclaró que gran parte del texto que se discute es de carácter simbólico, porque ya está cubierto por la Constitución y la legislación.

El Ministro señor Viera-Gallo explicó (...) la intención del Ejecutivo no es innovar en el estatuto juridico de las aguas en Chile, sino asegurar que el reconocimiento de los derechos de los pueblos e individuos a las aguas, conforme a la normativa actual.

Entonces la duda persiste, aunque anteriormente planteamos en una mirada teórica de que a pesar de todas las dificultades resulta positiva un reconocimiento constitucional de los pueblos indígenas como una muestra inequívoca de la valoración, apreció y de que integran la nación chilena, ahora que nos enfrentamos a este texto legal, ¿Cuál es la conveniencia de aprobar el reconocimiento constitucional de los pueblos indígenas? Si bien, la inclusión de estas normas jurídicas implica meras reiteraciones, salvo el Artículo 4 Incisos $1^{\circ}$ y $2^{\circ}$ nuevos, estas son valiosas, en la medida que dan más luces al intérprete de la Constitución, particularmente en el tema de la no discriminación. El constituyente por la importancia que le da al tema, no se basto con consagrarlo en el Artículo 19 No2, sino que lo repite en el Artículo 19 No16 Inc.3o (discriminaciones en materia laboral) y No22 (no discriminación en el tratamiento que da el Estado en materia económica).

\section{CONCLUSIONES}

Llegamos a la conclusión de que es positivo el reconocimiento constitucional de los pueblos indígenas, como una forma de reconocer y valorar el aporte que han significado las culturas precolombianas a la conformación de la nación chilena. Es una temática que hay que abordar por la importante población indígena presente en nuestro país, particularmente en la región de la Araucanía, aunque no hay que olvidar la importante cantidad de población indígena urbana, que se integra a nuestras ciudades, por lo que se les debe dar un adecuado espacio para que puedan expresar su identidad.

El camino del reconocimiento constitucional de los pueblos indígenas plantea varias dificultades y desafíos, es importante aprender de la experiencia de los demás países de América Latina, sin dejar de tener en cuenta que nuestras realidades son diversas. Me considero partidario del proyecto de reforma constitucional aprobado por la Comisión de Constitución, Legislación, Justicia y Reglamento del Senado, aunque dé la impresión de que todo cambia, pero nada cambia, yo creo que nos quedaremos con algo muy importante: el reconocimiento muy merecido a nuestro pueblos indígenas. 


\section{REFERENCIAS BIBLIOGRÁFICAS}

BazÁn, Víctor. Los Derechos de los Pueblos Indígenas en Argentina: Diversos Aspectos de la Problemática. Sus Proyecciones en los ámbitos Interno e Internacional, en: Boletín Mexicano de Derecho Comparado <en línea>, nueva serie, ańo XXXVI, nº. 108, septiembre-diciembre de 2003, [citado 7 de marzo de 2010]. Disponible en la World Wide Web: <http://www.juridicas.unam.mx/publica/librev/rev/boletin/cont/108/art/art1.pdf>

Carbonell, Miguel. La Constitucionalización de los Derecho Indígenas en América Latina: Una Aproximación Teórica, en Boletín Mexicano de Derecho Comparado <en línea>, nueva serie, año XXXVI, $\mathrm{n}^{\circ} 108$, septiembre-diciembre de 2003, [citado 6 de marzo de 2010]. Disponible en la World Wide Web: <http://www.juridicas.unam.mx/publica/librev/rev/boletin/cont/108/art/art2.pdf>

Donoso, Sebastián: Chile y el Convenio 169 de la OIT: reflexiones sobre un desencuentro. Santiago, Chile: Vicerrectoría de Comunicaciones y Asuntos Públicos, Pontificia Universidad Católica de Chile. Temas de la Agenda Pública, Año 3, No16, Abril 2008 [citado 8 de marzo de 2010]. Disponible en la World Wide Web: <http:// vinculosconlasociedad.uc.cl/documentos/5.pdf>

SEMPER, Frank. Los derechos de los pueblos indigenas de Colombia en la jurisprudencia de la Corte Constitucional, en Anuario de Derecho Constitucional Latinoamericano, Fundación Konrad-Adenauer, Bonn, Alemania, 2006, año 12 , Tomo II.

Silva Bascuñán, Alejandro. El Concepto de Pueblos Indígenas. Informe en Derecho. Santiago. Chile, 1992. Tratado de Derecho Constitucional. Tomo I -2da edición- Santiago, Chile: Editorial Jurídica de Chile, 1997. . Tratado de Derecho Constitucional. Tomo IV -2da edición- Santiago, Chile: Editorial Jurídica de Chile, 1997. . Tratado de Derecho Constitucional. Tomo XII -2da edición actualizada- Santiago, Chile: Editorial Jurídica de Chile, 2008.

Uriarte, Edurne. Introducción a la Ciencia Politica: la política en las sociedades democráticas. Madrid, España: Editorial Tecnos, 2002.

Vergara Blanco, Alejandro. Apuntes de Clase, Derecho Administrativo I. Santiago, Chile, Semestre I, 2009.

Weber, Max. El Político y el Cientifico. Madrid, España: Alianza Editorial, 2003.

Legislación

Constitución Política de los Estados Unidos Mexicanos de 1917, con las reformas de 2010.

Constitución Política de la República de Colombia de 1991, con las reformas de 1997.

Constitución de la nación Argentina, reformada el 22 de agosto de 1994.

Convenio 169 OIT.

Ley Indígena, No 19.253.

Documentos Oficiales

Informe de la Comisión de Constitución, Legislación, Justicia y Reglamento del Senado, recaído en dos proyectos de reforma constitucional, en primer trámite constitucional, sobre reconocimiento de los pueblos indígenas, Boletines 5.324-07 y 5.522-07 <en línea> [citado 27 de noviembre de 2010]. Disponible en la World Wide Web: <http://sil.senado.cl/cgi-bin/index_eleg.pl?5324-07\%20y\%205522 07\%20\%28refundidos\%29,1,,S>

Encuesta CASEN 2006 <en línea> [citado 7 de marzo de 2010] Disponible en la World Wide Web: < http://www. mideplan.cl/casen/publicaciones/2006/casen2006.pdf>. 
Censo 2002. Volumen I <en línea> [citado 7 de marzo de 2010]. Disponible en la World Wide Web: <http://www. ine.cl>.

Diccionario de la Real Academia de la Lengua Española <en línea> [citado 25 de febrero de 2010]. Disponible en la World Wide Web: <http://www.rae.es>.

Jurisprudencia Citada

Requerimiento Formulado por Diversos Diputados para que el Tribunal resuelva la constitucionalidad del Convenio No 169, Sobre Pueblos Indigenas y Tribales en países independientes, adoptado por la Organización Internacional del Trabajo. Tribunal Constitucional de Chile, ROL 309, 4 de Agosto de 2000.

Del Villar Mascardi, Waldo. Requerimiento de Inaplicabilidad por Inconstitucionalidad del artículo 61 de la Ley $N^{o}$ 20.000, sobre tráfico ilícito de estupefacientes y sustancias psicotrópicas. Tribunal Constitucional de Chile, ROL 1133, 18 de Noviembre de 2008.

Lincoqueo Huenumán, José. Requerimiento de Inaplicabilidad por Inconstitucionalidad respecto del Código Penal, de todos sus Códigos adjetivos, en especial del Código Procesal Penal y la Ley Orgánica sobre funcionamiento del Ministerio Público "en el territorio de los indígenas situados al sur del Bio- Bio". Tribunal Constitucional de Chile, ROL 1048, 13 de mayo de 2008.

Requerimiento de inconstitucionalidad presentado por treinta y cinco señores Diputados respecto del Estatuto de Roma de la Corte Penal Internacional, adoptado en dicha ciudad el 17 de julio de 1998. Tribunal Constitucional de Chile, ROL 346, 8 de Abril de 2002.

Oficio de la Cámara de Diputados: Control de constitucionalidad del proyecto de ley, aprobado por el Congreso Nacional, que modifica la Ley No 17.997, Orgánica Constitucional del Tribunal Constitucional. Tribunal Constitucional de Chile, ROL 1288, 25 de agosto de 2009. 